\title{
National Red Lists: the largest global market for IUCN Red List Categories and Criteria
}

\author{
Jon Paul Rodríguez ${ }^{1,2, *}$ \\ ${ }^{1}$ Centro de Ecología, Instituto Venezolano de Investigaciones Científicas, Apdo. 20632, Caracas 1020-A,Venezuela \\ ${ }^{2}$ Provita, Apdo. 47552, Caracas 1041-A, Venezuela
}

\begin{abstract}
The 2 major challenges currently confronting the International Union for Conservation of Nature (IUCN) with regard to the 'red listing' process are the taxonomic, and the geographic growth of the data base. Taxonomic growth refers to the objective of gradually assessing the risk of extinction of all the world's species and periodically repeating such assessments. Geographic growth refers to the increasing number of people around the world interested in performing extinction risk assessments for various groups of organisms in their region or country. The taxonomic challenge, although a large and demanding task, can be addressed by expanding and strengthening the networks of experts organized within the IUCN Species Survival Commission (SSC), which represents a significant scaling-up of a well-developed, known model. However, no current structure within the IUCN has the mandate to address the geographic challenge; this requires the creation of new structures or mechanisms. At least 5 key activities must be implemented to effectively integrate the diffuse network of national assessors into the global red listing process: (1) large-scale publicizing of the Guidelines for Application of IUCN Red List Criteria at Regional Levels, and encouraging the work of national assessors; (2) establishing the IUCN Species Programme as the primary trainer and certifier of multipliers; (3) delegating the majority of training to national institutions; (4) creating a virtual data clearing house for national red lists, seamlessly linked to the global list; and (5) consolidating the IUCN Species Programme as the primary endorser of national red list assessments. Hundreds of regional and national red lists will probably be produced in the next decade using the IUCN Red List Categories and Criteria, particularly because they are now recognized by international agreements such as the 2010 biodiversity target of the Convention on Biological Diversity and the United Nation's General Assembly Millennium Development Goals. By catalyzing this process, the IUCN would expand the information on the world's threatened species, while strengthening local scientific capacity for generating and using these data to support conservation action.
\end{abstract}

KEY WORDS: Assessment of extinction risk - Conservation priorities - IUCN Red List . National red lists · Threatened species

- Resale or republication not permitted without written consent of the publisher

\section{INTRODUCTION}

The International Union for Conservation of Nature (IUCN) led a major paradigm shift among the conservation community when it adopted quantitative thresholds and criteria for the designation of extinction risk categories for threatened species (Mace \& Lande 1991, IUCN 1994, 2001). Prior to this, threatened species definitions were largely subjective, and classifications were heavily influenced by the experience and knowledge of the assessors, often resulting in these experts making conflicting assessments. The current system allows for a clear separation of the scientific process of extinction risk assessment from the societal process of conservation priority setting and assigns categories to species in a manner that is objective, repeatable and transparent (Mace \& Lande 1991, IUCN 2001, IUCN Standards and Petitions Working Group 2008).

The IUCN Red List of Threatened Species (www. iucnredlist.org) has become a fundamental source of information on the global conservation status of plants and animals (Collar 1996, Lamoreux et al. 2003, de 
Grammont \& Cuarón 2006, Rodrigues et al. 2006). The fact that the Convention on Biological Diversity considers the 'change in status of threatened species' as one of the key indicators for judging the achievement of the 2010 biodiversity target (www.cbd.int/2010target), is just one example of the impressive policy influence of the IUCN Red List and the Red List Indices derived from it (Butchart et al. 2004, 2005, 2006, 2007).

The IUCN Red List Criteria are designed for the assessment of the global population of a species or a taxon below the species level (IUCN Standards and Petitions Working Group 2008) and the IUCN Red List of Threatened Species annually reports on the global status of the world's plants and animals. Policies for the conservation of threatened species, however, typically are implemented at national or sub-national (e.g. province, state, municipality) levels, or in some cases across regions that include more than one country (e.g. the European Union). As one might expect, different categories might be appropriate for a species that inhabits several regions. To evaluate extinction risk at national or regional levels, assessors must follow specific guidelines on how to interpret the IUCN Red List Criteria within their geographical boundaries (Gärdenfors et al. 2001, IUCN 2003, Miller et al. 2006, 2007).

Two major challenges currently confront the IUCN with regards to 'red listing': (1) the taxonomic and (2) the geographic growth of the data base. Taxonomic growth refers to the objective of gradually assessing the risk of extinction of all the world's species and periodically repeating such assesments. Systematic assessments of several major taxonomic groups have either been carried out or are in the process. For example, BirdLife International (formerly International Council for Bird Preservation and BirdLife) assessed the risk of extinction of all the world's birds in 1988, 1994, 2000 and 2004 (Collar \& Andrew 1988, Collar et al. 1994, BirdLife 2000, BirdLife International 2004), and the Global Amphibian Assessment completed its first global assessment in 2004 (IUCN et al. 2006). The number of threatened taxa in the IUCN Red List of Threatened Species increased from 10533 in 1996-1998 to 16306 in 2007, primarily as a result of recent systematic assessments of several groups of plants, amphibians and fishes (IUCN 2007). With global assessments for mammals, reptiles, marine organisms and freshwater biodiversity currently underway, this number will surely increase in the years to come. In 2008, for example, extinction risk assessments of all the world's mammals, cycads, groupers, freshwater crabs, reefbuilding corals, sharks, rays and skates, are expected (S. N. Stuart pers. comm.).

By 2007, 41415 (or 3\%) of the 1589361 known species of animals and plants had been assessed for the IUCN Red List of Threatened Species (IUCN 2007). Vertebrates are the best-documented group, as $42 \%$ of described species have been evaluated, but only $4 \%$ of plants and $<1 \%$ of invertebrates have been examined (Fig. 1). On average, $39 \%$ of assessed species have been classified as threatened. If this proportion were constant across all taxonomic groups, the number of threatened species listed by the IUCN would eventually increase from the 2007 value of 16306 to several hundreds of thousands of species.

The Species Survival Commission (SSC) of IUCN is designed to meet the challenge posed by the taxonomic growth of the IUCN Red List: specialist groups are predominantly organized around taxonomic groups (http://cms.iucn.org/about/work/programmes/ species/about_ssc/index.cfm), and have established global networks of experts capable of leading assessments of their species of interest. Though not all specialist groups are equally developed or experienced and not all taxa have specialist groups, there exists a platform for organizing experts around species groups and using these networks to assess species' extinction risk. The task here is to scale-up existing structures. Surely not a trivial task, but one based on a well-developed, known model.

The geographic challenge of red listing is more difficult, as no formal structure within the IUCN has addressed it systematically in the past. This challenge refers to responding to an increasing number of people around the world interested in performing extinction risk assessments for various groups of organisms in their region or country (for simplicity, hereafter referred to as 'national assessments' - although they may also include larger or smaller regions). In Europe alone, 3562 current and historical threatened species lists have been reported (Köppel et al. 2003). At least 99 countries ( $\sim 50 \%$ of the countries of the world) have developed a red list for at least 1 taxonomic group (WCMC 1994, Miller et al. 2007, T. Zamin pers. comm.). It is not unlikely that in the next decade hundreds of

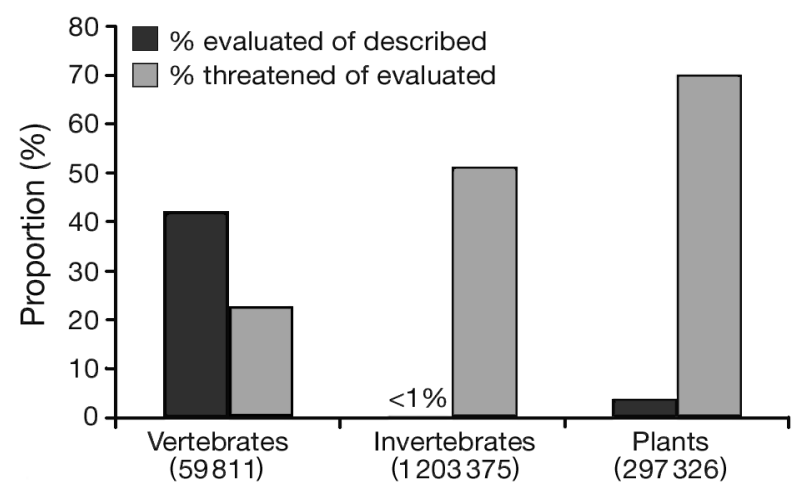

Fig. 1. Proportion of described species of vertebrates, invertebrates and plants that have been evaluated for the IUCN Red List of Threatened Species, and proportion of evaluated species that have been classified as threatened (IUCN 2007).

Numbers in parentheses: no. of species described 
new national red lists might be produced and that the IUCN will be asked to assist national assessors in the process and to develop standards for integrating this information into the global Red List. In contrast to the SSC, however, national red lists are (1) organized geographically rather than taxonomically, and (2) often carried out by people outside of the IUCN network, including governmental agencies, non-governmental organizations (NGOs), and individuals. Thus, there is no concrete 'place' for national assessments in the global red listing effort, and the work of national and global assessors does not always coincide (Rodríguez et al. 2000). A National Red List Working Group (NaRLiWoG) was established within SSC in 2006, with the mandate to build linkages which will enable data flow from national red lists to the global IUCN Red List and provide training in red listing around the world to enhance local capacity for biodiversity assessment. At this point, however, NaRLiWoG is only beginning to think about how to confront the geographic challenge of red listing.

There are a number of overlapping issues that should be considered when designing strategies for effectively integrating the diffuse network of national assessors into the global red listing process. To keep the discussion as clear as possible, I have tried to avoid repetition and to focus on the theme of each subsection. But these issues are undoubtedly linked and overlap with one another.

Before exploring these issues in more detail, it is important to point out that red listing must always be examined critically and that species assessments are more likely to be reliable if they are carried out by groups of experts working together, using standardized and transparent protocols (Regan et al. 2005). Some important criticisms of Red Lists have recently been made, highlighting the limitations of applying IUCN Red List Categories to long-lived species and the assessment of extinction risk at the global level without adequate data across the entire range of a species (Webb \& Carrillo 2000, Mrosovsky 2003, Kozlowski 2008, Seminoff \& Shanker 2008).

\section{PUBLICIZING THE GUIDELINES FOR APPLICATION OF IUCN RED LIST CRITERIA AT REGIONAL LEVELS AND ENCOURAGING THE WORK OF NATIONAL ASSESSORS}

Although guidelines have been available in various draft forms and as a formal document for almost a decade (Gärdenfors et al. 1999, 2001, IUCN 2003), the community of national assessors is largely unaware of their existence, and they frequently apply the global criteria nationally without considering the regional guidelines (Miller et al. 2007). Lack of knowledge of the rules will hinder the correct application of the guidelines (Regan et al. 2005). Furthermore, there is often confusion regarding the fact that the purpose of the IUCN criteria is to rank species according to different levels of extinction risk, thus separating the process of assessing threat status from setting conservation priorities (Miller et al. 2006, 2007). Willingness to widely adopt IUCN Categories and Criteria (IUCN 2001) appears to be limited by ignorance of the nature and motivation of threatened species categorization systems, inadequate access to scientific literature in some parts of the world, and resistance to implementing foreign methods over those developed locally (de Grammont \& Cuarón 2006). Poor data availability, 'inadequate' classification of some taxa by the criteria, and a widespread belief that application of the criteria in small regions will lead to an overestimation of extinction risk are also cited as explanations for avoiding, adapting or modifying the IUCN system (Miller et al. 2007).

A publicity campaign that encourages national assessors to apply the IUCN Categories and Criteria, highlighting the justification and advantages of using the regional guidelines, should be a central component of future efforts. This campaign could be delivered through the IUCN membership, emphasizing that national red lists are a key component of the global red listing process. At the very least, national and global categories should be identical for endemic species (IUCN 2003, Rodríguez et al. 2000), and the information generated in national red lists should naturally flow to the global list. A public invitation to national assessors to contribute 'their' endemic species to the global list would provide an incentive for achieving the standards of global Red Lists, thus encouraging national assessors to become familiar with the IUCN Categories and Criteria. An invitation to also publish their complete national lists in a website hosted by the IUCN would encourage the application of the regional guidelines (see 'Creating a virtual data clearing house for national red lists'). In other words, an offer to recognize the work of national assessors as one of the central elements of the publicity campaign would serve the double function of increasing the diversity of data inputs to the global Red List, and improving the knowledge of national assessors regarding the IUCN Categories and Criteria, as well as the regional guidelines.

\section{ESTABLISHING THE IUCN SPECIES PROGRAMME AS THE PRIMARY TRAINER AND CERTIFIER OF MULTIPLIERS}

National assessors have identified the lack of training in the proper use of the criteria and regional guidelines as one of their primary limitations (Miller 
et al. 2007). The IUCN Species Programme, in turn, should be the natural source for all primary training in the correct application of IUCN Red List Categories and Criteria, as well as the regional guidelines.

Primary training should comprise 3 key activities: (1) design and distribution of a basic training package, (2) curriculum development and implementation of a basic short course on red listing (including application of the regional guidelines), and (3) certification of trainers in IUCN Red List Categories and Criteria. Based on the accumulated experience of the IUCN Species Programme, especially through its interaction with a diversity of SSC Specialist groups and numerous teams of national assessors, there is nobody better equipped to identify the key issues, questions and skills required for carrying out an assessment or teaching others how to do it.

Although reliance on local institutions is fundamental for achieving a true multiplying effect (see following section), the IUCN should set the standards for learning and teaching how to perform risk assessments for threatened species. Familiarity with the basic training package and approval of the basic short course offered by the IUCN Species Programme would be required for a person to be certified as a trainer in IUCN Red List Categories and Criteria. The first set of certified multipliers would be trained by experienced staff members of the IUCN Species Programme through the implementation of a series of basic short courses throughout the world. This could be in association with IUCN regional offices, or in collaboration with governmental agencies or NGOs experienced in red listing. The core group of certified trainers would be qualified to replicate the course in their country or region, and certify the next generation of trainers. The basic training package would be accessible for downloading, free of cost, through the IUCN website. Initially, the basic training package should be available in the 3 IUCN official languages (Spanish, English and French), although translation into other languages should be encouraged.

\section{DELEGATING THE MAJORITY OF TRAINING TO NATIONAL INSTITUTIONS}

Strengthening the red listing community worldwide requires a well-distributed network of certified trainers in all continents. Existing conservation capacity is located predominantly in the developed world (Gaston \& May 1992, Rodríguez et al. 2005, Mendez et al. 2007), precisely in the same regions where most national red lists have been produced (WCMC 1994, Miller et al. 2007, T. Zamin pers. comm.). Increasing the capacity of people in biodiversity-rich regions requires expanding the availability of training opportunities in collaboration with local institutions.

While I have proposed that primary training should be a responsibility of the IUCN Species Programme, national assessments should be carried out predominantly in their respective countries and training opportunities should be readily available throughout the world. In developing countries, personnel associated with universities tend to be relatively more stable than those in governmental institutions or NGOs. Thus, creation of programs for the certification of trainers in IUCN Red List Categories and Criteria in association with local universities would probably be more likely to persist in the long term. In some countries, however, the best partners might be well-established NGOs or the government. Courses that offer academic credits from the host university would also increase their attractiveness.

The role of the IUCN Species Programme would be to identify and certify trainers in key locations throughout the world, with the understanding that they would become multipliers by offering periodic, short, basic courses through their institutions. A standardized test would be designed by the IUCN Species Programme (in collaboration with other relevant stakeholders and experts) to evaluate the performance of course participants, and a minimum score would be required to achieve certification. Ideally, the certification test would be overseen by the IUCN Species Programme and, where possible, be available for taking online. In places where online access is unavailable, the development of alternative methods may be required.

Anyone who achieved certification would be qualified to teach others, but by supervising the certification test process, the IUCN Species Programme would be able to monitor the growth and development of programs for the certification of trainers in IUCN Red List Categories and Criteria.

\section{CREATING A VIRTUAL DATA CLEARING HOUSE FOR NATIONAL RED LISTS}

The establishment of an online database of red listing information would be an efficient method for improving communication between the IUCN Species Programme and the global community of national assessors (Rodríguez et al. 2000, Miller et al. 2007). The website would include a mechanism for the submission of national lists to the IUCN Species Programme, in order to improve the integration of national and global assessments (especially for endemic species). Anyone conducting a search for a species would be able to access its status in all the countries where it has been 
assessed, as well as the global Red List category. To minimize taxonomic differences, national assessors interested in having their data added to the website would have to follow the taxonomy of the global Red List.

The website's other functions would include providing answers to frequently asked questions, offering contact information of national assessors in different countries, and providing links to an online discussion group dedicated to national red listing, the IUCN Red List Program, and the global Red List. People conducting searches in the global Red List would also be able to automatically retrieve the Red List category of a species in all countries where it has been assessed (and loaded to the online database).

\section{CONSOLIDATING THE IUCN SPECIES PROGRAMME AS THE PRIMARY CERTIFIER OF NATIONAL RED LIST ASSESSMENTS}

A major strength of the IUCN Red List of Threatened Species is that great care is put into assuring the quality of the data and the experience of the assessors. The group of people coordinating the assessments is relatively small and the criteria used are relatively uniform. The result is red list categories that are defensible and that people generally agree with. In the case of national assessments, however, this is not so straightforward. National assessors have often adapted the IUCN criteria to meet specific needs (Miller et al. 2007) and even if the criteria were not modified, it is not easy to know if they were applied correctly without examining the underlying data.

Part of this problem is solved if assessors demonstrate their proper use of the criteria in the documentation that accompanies their assessments (IUCN 2003, IUCN Standards and Petitions Working Group 2008). But the fact that a country decides to develop a red list using its own criteria should not be a motive for complete exclusion from a website of national red lists.

The solution might lie in the development of a method for peer-reviewing national red lists by the global network of certified trainers. The 'gold standard' would be national red lists developed by a certified trainer in IUCN Red List Categories and Criteria; these lists would be published in the national red lists website without question, but could be subject to challenges in the same way global listings can be challenged (IUCN Standards and Petitions Working Group 2008). National lists not developed by a certified trainer would not be identified as meeting the gold standard until they were endorsed by at least 3 certified trainers from different countries. Lists uploaded without seeking the endorsement of any trainer, but for which the authors claimed to have used IUCN Red List Categories and Criteria, would have to be peerreviewed by at least 3 certified trainers recommended by the IUCN Species Programme. Lists that did not follow the IUCN Red List Categories and Criteria, but which their authors wanted to place on the website, would be uploaded and their data clearly highlighted as red list categories that did not meet the IUCN standard. In this case, the category proposed by the assessors for endemic species would not be expected to be identical to the category of the global Red Lists.

\section{CONCLUSION}

The motivation for developing a system such as that described here would be to offer a platform for making available threatened species data developed nationally, while creating incentives for assessors to follow the IUCN Red List process. Hundreds of regional and national red lists will probably be produced in the next decade using the IUCN Red List Categories and Criteria, particularly because Red Lists are now recognized by international agreements such as the 2010 biodiversity target of the Convention on Biological Diversity or the United Nation's General Assembly Millennium Development Goals. By taking the lead in providing guidance, training, publication outlets, and support of the red listing process, the IUCN Species Programme would increase the quantity and quality of data on the world's threatened species, while strengthening the scientific capacity of local institutions for generating and using these data to support conservation action.

Acknowledgements. I am grateful to S. N. Stuart for his thoughts and suggestions during the preparation of this article; he, M. Godfrey and 2 anonymous reviewers made helpful suggestions that improved a previous version of the manuscript. Provita is a member of the Wildlife Trust Alliance.

\section{LITERATURE CITED}

BirdLife (2000) Threatened birds of the world. Lynx Edicions, Barcelona

BirdLife International (2004) Threatened birds of the world 2004. CD-ROM. BirdLife International, Cambridge

Butchart SHM, Stattersfield AJ, Bennun LA, Shutes SM and others (2004) Measuring global trends in the status of biodiversity: Red List indices for birds. PLoS Biol 2:e383

> Butchart SHM, Stattersfield AJ, Baillie J, Bennun LA and others (2005) Using Red List Indices to measure progress towards the 2010 target and beyond. Philos Trans R Soc Lond B Biol Sci 360:255-268

Butchart SHM, Akçakaya HR, Kennedy E, Hilton-Taylor C (2006) Biodiversity indicators based on trends in conservation status: strengths of the IUCN Red List index. Conserv Biol 20:579-581 
Butchart SHM, Akçakaya HR, Chanson J, Baillie J and others (2007) Improvements to the Red List index. PLoS ONE 2(1):e140

Collar NJ (1996) The reasons for red data books. Oryx 30: 121-130

Collar NJ, Andrew P (1988) Birds to watch: the ICBP world checklist of threatened birds. International Council for Bird Preservation (ICBP) and IUCN, Cambridge

Collar NJ, Crosby MJ, Stattersfield AJ (1994) Birds to watch 2. The World List of Threatened Birds. BirdLife International, Cambridge

de Grammont PC, Cuarón AD (2006) An evaluation of threatened species categorization systems used on the American continent. Conserv Biol 20:14-27

Gärdenfors U, Rodríguez JP, Hilton-Taylor C, Hyslop C, Mace G, Molur S, Poss S (1999) Draft guidelines for the application of IUCN Red List Criteria at national and regional levels. Species 31-32:58-70

Gärdenfors U, Hilton-Taylor C, Mace GM, Rodríguez JP (2001) The application of IUCN Red List Criteria at regional levels. Conserv Biol 15:1206-1212

Gaston KJ, May RM (1992) Taxonomy of taxonomists. Nature 356:281-282

IUCN (1994) IUCN Red List Categories. Species Survival Commission. IUCN, Gland

IUCN (2001) IUCN Red List Categories and Criteria: Version 3.1. Species Survival Commission, IUCN, Gland

IUCN (2003) Guidelines for application of IUCN Red List Criteria at regional levels: Version 3.0. IUCN Species Survival Commission, IUCN, Gland

IUCN (2007) 2007 IUCN Red List of Threatened Species. www.iucnredlist.org. Downloaded 16 January 2008

IUCN Standards and Petitions Working Group (2008) Guidelines for using the IUCN Red List Categories and Criteria. Version 7.0. Prepared by the Standards and Petitions Working Group of the IUCN SSC Biodiversity Assessments Sub-Committee in August 2008. Available at: http://intranet.iucn.org/webfiles/doc/SSC/RedList/ RedListGuidelines.pdf

IUCN, Conservation International, NatureServe (2006) Global amphibian assessment. www.globalamphibians. org. Downloaded 3 November 2006

Köppel C, Jansen F, Burton J, Schnittler M, Hirneisen N (2003) A statistical survey on European red lists. In: Iongh HHD, Bánki OS, Bergmans W, van der Werff ten Bosch MJ (eds) The harmonization of Red Lists for Threatened Species in Europe. The Netherlands Commission for Interna-

Editorial responsibility: Matthew Godfrey,

Beaufort, North Carolina, USA tional Nature Protection, Leiden

Kozlowski G (2008) Is the global conservation status assessment of a threatened taxon a utopia? Biodivers Conserv $17: 445-448$

Lamoreux J, Akçakaya HR, Bennun L, Collar NJ and others (2003) Value of the IUCN Red List. Trends Ecol Evol 18: 214-215

Mace GM, Lande R (1991) Assessing extinction threats: toward a reevaluation of IUCN threatened species categories. Conserv Biol 5:148-157

> Mendez M, Gómez A, Bynum N, Medellín R, Porzecanski AL, Sterling E (2007) Availability of formal academic programs in conservation biology in Latin America. Conserv Biol 21:1399-1403

Miller RM, Rodríguez JP, Aniskowicz-Fowler T, Bambaradeniya $C$ and others (2006) Extinction risk and conservation priorities. Science 313:441

Miller RM, Rodríguez JP, Aniskowicz-Fowler T, Bambaradeniya $\mathrm{C}$ and others (2007) National threatened species listing based on IUCN Criteria and Regional Guidelines: current status and future perspectives. Conserv Biol 21:684-696

Mrosovsky N (2003) Predicting extinction: fundamental flaws in IUCN's Red List system, exemplified by the case of sea turtles. http://members.seaturtle.org/mrosovsky/

> Regan TJ, Burgman MA, McCarthy MA, Master LL, Keith DA, Mace GM, Andelman SJ (2005) The consistency of extinction risk classification protocols. Conserv Biol 19: 1969-1977

> Rodrigues ASL, Pilgrim JD, Lamoreux JF, Hoffmann M, Brooks TM (2006) The value of the IUCN Red List for conservation. Trends Ecol Evol 21:71-76

> Rodríguez JP, Ashenfelter G, Rojas-Suárez F, García Fernández JJ, Suárez L, Dobson AP (2000) Local data are vital to worldwide conservation. Nature 403:241

Rodríguez JP, Simonetti JA, Premoli A, Marini MA (2005) Conservation in Austral and Neotropical America: building scientific capacity equal to the challenges. Conserv Biol 19:969-972

Seminoff JA, Shanker K (2008) Marine turtles and IUCN red listing: a review of the process, the pitfalls, and novel assessment approaches. J Exp Mar Biol Ecol 356:52-68

WCMC (World Conservation Monitoring Centre) (1994) Biodiversity data sourcebook. World Conservation Press, Cambridge

- Webb GJW, Carrillo E (2000) Risk of extinction and categories of endangerment: perspectives from long-lived reptiles. Popul Ecol 42:11-17

Submitted: January 28, 2008; Accepted: August 7, 2008 Proofs received from author(s): September 25, 2008 